\title{
Pengaruh Kepercayaan, Persepsi Harga, dan Kinerja Operasional Terhadap Minat Beli Pelanggan Lazada
}

\author{
Cyntia Sari dan Rodhiah \\ Program Studi Manajemen Fakultas Ekonomi dan Bisnis \\ Universitas Tarumanagara \\ Email: cyntia.115160188@stu.untar.ac.id
}

\begin{abstract}
The purpose of this study is to determine the trust, perceived price and operational performance have a positive influence on buying interest in Lazada customers in West Jakarta. This research is a Lazada customer who lives in West Jakarta. The sample in this study were 100 people using purposive sampling technique. Data collection techniques are carried out by distributing questionnaires using Google Form through social media Twitter and also Instagram. Data were analyzed using SEM with PLS-SEM analysis media. The results of this study indicate that trust and operational performance affect buying interest positively and significantly, while price perceptions do not affect buying interest positively and significantly. Researchers hope that this research can be useful for further research and can also be useful to increase the knowledge of readers.
\end{abstract}

Keywords: Purchase Intention, Trust, Perceived Price, Operational Performance

Abstrak: Tujuan dari penelitian ini adalah untuk mengetahui kepercayaan, persepsi harga dan kinerja operasional memiliki pengaruh positif terhadap minat beli pada pelanggan Lazada di Jakarta Barat. Penelitian ini adalah pelanggan Lazada yang berdomisili di daerah Jakarta Barat. Sampel pada penelitian ini adalah sebanyak 100 orang dengan menggunakan teknik purposive sampling. Teknik pengumpulan data dilakukan dengan menyerbarkan kuesioner menggunakan Google Form melalui media sosial Twitter dan juga Instagram. Data dianalisis menggunakan SEM dengan media analisis PLS-SEM. Hasil pada penelitian ini menunjukkan bahwa kepercayaan dan kinerja operasional mempengaruhi minat beli secara positif dan signifikan, sedangkan persepsi harga tidak mempengaruhi minat beli secara positif dan signifikan. Peneliti berharap agar penelitian ini dapat berguna untuk penelitian selanjutnya dan juga dapat berguna untuk menambah pengetahuan pembaca.

Kata Kunci: Minat beli, Kepercayaan, Persepsi Harga, Kinerja Operasional

\section{LATAR BELAKANG}

Munculnya e-commerce telah membuat pembelian online menjadi aktivitas paling populer ketiga setelah email dan penjelajahan web (Jamali, 2014). Banyak perusahaan $e$ commerce yang berkembang di Indonesia seperti salah satunya adalah Lazada. Lazada merupakan salah satu perusahaan e-commerce yang mampu bersaing di pasar online di Indonesia. Lazada sendiri menempati peringkat ke 4 dalam data Persaingan Toko Online di Indonesia pada Kuartal 4 tahun 2019 (Iprice Insights, 2020). 
Tabel 1. Persaingan Toko Online di Indonesia pada Kuartal 4 tahun 2019

\begin{tabular}{|c|c|c|}
\hline Toko Online & $\begin{array}{c}\text { Pengunjung Website } \\
\text { Bulanan }\end{array}$ & $\begin{array}{c}\text { Ranking Apps } \\
\text { Store }\end{array}$ \\
\hline Shopee & 72.973 .300 & 1 \\
\hline Tokopedia & 67.900 .000 & 2 \\
\hline BukaLapak & 39.263 .300 & 3 \\
\hline Lazada & 28.383 .300 & 4 \\
\hline Blibli & 26.863 .300 & 5 \\
\hline
\end{tabular}

Sumber: Iprice Insights

Dalam suatu pasar baik dalam pasar yang menghubungkan penjual dan pembeli secara langsung ataupun secara online ataupun e-commerce, minat beli merupakan salah satu faktor yang penting dalam kegiatan pembelian karena minat beli merupakan dasar dalam suatu keputusan pembelian. Menurut Close dan Kukar-Kinney (2010 dalam Ariffin, Mohan \& Goh, 2018:311) minat pembelian online berasal dari minat pembelian. Dan juga mendefiniskan minat beli online sebagai minat membeli online untuk membeli barang dan jasa melalui internet atau kereta belanja virtual. Meskaran (2013 dalam Ariffin, Mohan \& Goh, 2018:311) mendefinisikan minat beli sebagai kesiapan pelanggan untuk membeli melalui internet. Minat beli itu sendiri dapat dipengaruhi oleh persepsi harga, kepercayaan, kinerja operasional, risiko, electronic word of mouth, persepsi nilai, perilaku konsumen, promosi, lokasi, kualitas pelayanan dan kualitas produk.

Ketika melakukan pembelian dalam e-commerce, konsumen harus memiliki kepercayaan terhadap suatu tempat penjualan baik secara online maupun offline atapun terhadap suatu produk tertentu agar dapat menimbulkan terjadinya minat beli. Kepercayaan keseluruhan konsumen tentang kredibilitas dan keandalan penjual dalam berinteraksi di situs web ( $e$ commerce) akan memenuhi harapan nilai mereka dalam pertukaran kontribusi keuangan, fisik dan psikologis (Mahmud dkk., 2019).

Selalu ada risiko keuangan yang signifikan saat berinteraksi dengan memberikan informasi pribadi ke suatu situs web e-commerce (Mahmud dkk., 2019). Adanya risiko keuangan sangat menghalangi minat positif konsumen untuk membeli melalui e-commerce. Mahmud dkk mendefinisikan persepsi harga sebagai persepsi melalui evaluasi komparatif trade-off antara manfaat yang dicapai dan biaya pengeluaran yang dihabiskan untuk menyelesaikan tugas yang ditargetkan. Jika terjadi masalah keamanan maupun masalah dalam hal pembelian pada Lazada, teknisi Lazada akan berusaha memberikan penanganan yang cepat agar memberikan kepuasan kepada pelanggan Lazada.

Ada dasar-dasar dalam pengendalian keamanan pada industri e-commerce. Pengendalian ini diterapkan untuk mengendalikan risiko pencurian identitas dalam perdagangan di $e$ commerce karena konsumen mungkin merasakan permasalahan dalam hal kinerja operasional (Saleh (2013 dalam Mahmud, Dwivendi \& Kumar, 2019:1346). Kinerja operasional yang dimaksud dalam penelitian ini adalah terdiri dari pengendalian kualitas produk atau layanan, pengembangan produk baru, kepuasan pelanggan, retensi karyawan dan pengiriman cepat (Paul \& Anantharaman (2003 dalam Ram \& Gupta, 2019:97)

Penelitian ini meneliti pengaruh persepsi kepercayaan, persepsi harga, dan kinerja operasional terhadap minat beli pada pelanggan Lazada karena adanya perbedaan persepsi kepercayaan antar pembeli dan juga kurangnya kunjungan website Lazada dibandingkan $e$ commerce lainnya membuat peneliti tertarik untuk meneliti tentang pengaruh persepsi 
kepercayaan, persepsi harga dan kinerja operasional terhadap minat beli pada pelanggan Lazada.

\section{KAJIAN TEORI}

Kepercayaan. Mahmud et al. (2019) menyatakan bahwa kepercayaan dapat di definisikan disini sebagai tingkat dimana konsumen memiliki keyakinan kongnitif, afektif, dan perilaku dalam penjual elektronik karena penerapan mekanisme pengendalian pencurian identitas sehingga interaksi dan transaksi mereka dalam e-commerce bebas dari semua risiko yang mungkin timbul dari serangan peretas. Lien et al. (2015) Kepercayaan mengacu pada keyakinan positif tentang keandalan dan ketergantungan seseorang atau suatu objek. Kaitan antara kepercayaan terhadap minat beli. Tong dan Su (2018) menyatakan bahwa kepercayaan konsumen mengenai konsep perdagangan yang adil dan atribut produk dapat mempengaruhi minat beli pelanggan. Hasil serupa dengan Mahmud et al (2018) yang menyatakan bahwa kepercayaan memiliki pengaruh yang positif signifikan pada minat beli konsumen dalam lingkungan e-commerce. Untuk itu, yang menjadi hipotesis penelitian adalah:

\section{H1: Kepercayaan memiliki efek positif yang signifikan terhadap Minat beli pada pelanggan Lazada}

Persepsi Harga. Zietsman dkk (2019) menyatakan bahwa persepsi harga dapat dideskripsikan sebagai penilaian subyektif pelanggan tentang kewajaran harga untuk suatu produk atau layanan dibandingkan dengan harga referensi pesaing. Harjati \& Venesia (2015) persepsi harga adalah persepsi mengenai harga bagaimana pelanggan memandang harga tertentu (tinggi, rendah, wajar) memiliki pengaruh kuat terhadap minat beli dan kepuasan dalam pembelian. Kaitan antara persepsi harga terhadap minat beli. Jamaludin dkk (2015) menyatakan bahwa pengalaman positif dan rekomendasi dari teman sendiri atau rekomendasi dari Lembaga (media masa, pemerintah dan lain sebagainya) dapat membangun minat beli seseorang. Mahmud et al (2018) menyatakan hasil persepsi harga memiliki pengaruh yang positif signifikan pada minat beli konsumen dalam lingkungan e-commerce. Untuk itu, yang menjadi hipotesis penelitian adalah:

\section{H2: Persepsi harga memiliki efek negatif yang signifikan pada Minat beli pada pelanggan} Lazada.

Kinerja operasional. Ram \& Gupta (2019) menyatakan bahwa kinerja operasional meliputi kualitas produk/layanan, pengembangan produk baru, kepuasan pelanggan, retensi karyawan, dan pengiriman cepat. Camara et al. (2015) Kinerja operasional dapat didefinisikan sebagai cara perusahaan dapat dengan cepat memodifikasikan sebuah produk untuk memenuhi kebutuhan pelanggan, dengan cepat meluncurkan produk baru ke pasar, menanggapi perubahan permintaan, meningkatkan waktu pengiriman, mengurangi produksi atau mentransfer waktu, atau meningkatkan layanan keseluruhan yang disediakan kepada pelanggan akhir. Kaitan antara kinerja operasional terhadap minat beli. Mahmud et al (2018) menyatakan bahwa kinerja operasi memiliki pengaruh yang positif signifikan pada minat beli konsumen dalam lingkungan e-commerce. Untuk itu, yang menjadi hipotesis penelitian adalah:

H3: Kinerja Operasional memiliki efek positif yang signifikan terhadap Minat beli pada pelanggan Lazada. 
Berdasarkan uraian kaitan antar variabel di atas, maka model penelitian yang digunakan dalam penelitian ini adalah sebagai berikut:

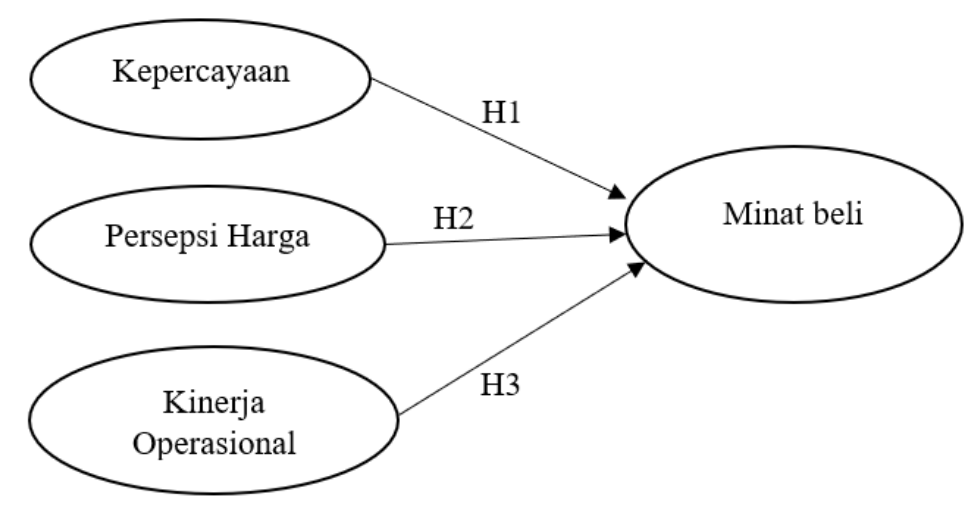

Gambar 1. Model Penelitian

\section{METODOLOGI}

Penelitian ini merupakan penelitian deskriptif dengan pendekatan cross sectional. Populasi yang akan dilibatkan yaitu pelanggan Lazada yang berdomisili di Jakarta Barat. Pengambilan sampel dengan metode non-probability sampling dengan metode purposive sampling. Teknik penyebaran data dengan menggunakan google form melalui media sosial Twitter dan Instagram. Penelitian ini menggunakan sampel sebanyak 100 sampel. Dari jumlah 100 responden yang digunakan dalam penelitian ini, mayoritas responden berjenis kelamin wanita $(88 \%)$ dan pria (12\%), berusia di antara 20-25 tahun (57\%) dan mayoritas responden seorang mahasiswa/i (79\%).

Tabel 2. Indikator Pengukuran Variabel

\begin{tabular}{|c|c|c|}
\hline Variabel & Item & Sumber \\
\hline Kepercayaan & $\begin{array}{l}5 \text { item (dapat diandalkan } \\
\text { dalam melindungi dari peretas } \\
\text { (hacker), dapat melindungi } \\
\text { dari pencurian identitas, akan } \\
\text { melakukan tindakan jika } \\
\text { terjadi pencurian identitas, } \\
\text { bertanggung jawab penuh atas } \\
\text { segala jenis rasa tidak aman } \\
\text { selama transaksi, merasa } \\
\text { nyaman saat berinteraksi) }\end{array}$ & $\begin{array}{l}\text { Mahmud, Dwivedi, Kumar, } \\
\text { Davies, Rana \& Baabdullah. }\end{array}$ \\
\hline Persepsi Harga & $\begin{array}{l}5 \text { item (harga produk/layanan } \\
\text { yang dibeli masuk akal, harga } \\
\text { produk/layanan yang dibeli } \\
\text { memuaskan, } \\
\text { produk/layanan yang dibeli } \\
\text { terbayar (senilai dengan } \\
\text { kualitas), merasa puas dengan } \\
\text { uang yang di habiskan } \\
\text { dibandingkan dengan nilai } \\
\text { yang diperoleh, imbalan } \\
\text { antara uang yang dihabiskan }\end{array}$ & $\begin{array}{l}\text { Mahmud, Dwivedi, Kumar, } \\
\text { Davies, Rana \& Baabdullah. }\end{array}$ \\
\hline
\end{tabular}




\begin{tabular}{|c|c|c|}
\hline & $\begin{array}{l}\text { dan nilai yang diperoleh dapat } \\
\text { diterima.) }\end{array}$ & \\
\hline Kinerja Operasional & $\begin{array}{l}5 \text { item (pengoperasiannya } \\
\text { berguna, proses pemesanan } \\
\text { yang masuk akal, memuaskan } \\
\text { untuk melakukan pemesanan, } \\
\text { semua interaksi untuk } \\
\text { melakukan pembelian dapat } \\
\text { diterima, senang dengan } \\
\text { waktu yang dihabiskan dalam } \\
\text { melakukan pembelian.) }\end{array}$ & $\begin{array}{l}\text { Mahmud, Dwivedi, Kumar, } \\
\text { Davies, Rana \& Baabdullah. }\end{array}$ \\
\hline Minat Beli & $\begin{array}{l}5 \text { item (ingin membeli, } \\
\text { senang dengan pembelian, } \\
\text { puas dengan pembelian, akan } \\
\text { terus membeli, ide yang } \\
\text { bagus untuk membeli } \\
\text { produk.) }\end{array}$ & $\begin{array}{l}\text { Mahmud dkk \& Chen \& } \\
\text { Teng. }\end{array}$ \\
\hline
\end{tabular}

\section{HASIL UJI STATISTIK}

Analisis validitas dan reliabilitas yang di uji menggunakan convergent validity, discriminant validity, loading factors dan composite reliability menghasilkan seluruh variabel dan indikator dalam penelitian ini valid digunakan dan seluruh variabel yang digunakan dalam penelitian ini juga dinyatakan reliabel.

Nilai R-square pada variabel Minat beli berada pada golongan sedang yang memiliki nilai sebesar 0,589. Hasil uji effect size seluruh variabel memiliki effect size yang lemah. Nilai effect size pada variabel kepercayaan sebesar 0,136, nilai effect size pada variabel kinerja operasi sebesar 0,080 dan nilai effect size pada variabel persepsi harga memiliki nilai effect size sebesar dan 0,025 . Hasil uji predictive relevance dapat mengukur dengan baik karena hasil yang didapatkan dari uji predictive relevance variabel minat beli adalah 0,359 . Hasil uji path coefficients menyatakan bahwa terdapat hubungan positif antara persepsi harga dengan minat beli yang memiliki nilai sebesar 0,161 . Terdapat juga hubungan positif antara kinerja operasi dengan minat beli yang memiliki nilai sebesar 0,337 . Dan juga terdapat hubungan positif antara kepercayaan dengan minat beli yang memiliki nilai sebesar 0,350 .

Tabel 3. Hasil Pengujian Hipotesis

\begin{tabular}{|c|c|c|}
\hline Variabel & $t$-value & $p$-value \\
\hline Kepercayaan $\rightarrow$ Minat Beli & 3,882 & 0,000 \\
\hline Persepsi Harga $\rightarrow$ Minat Beli & 1,311 & 0,190 \\
\hline $\begin{array}{c}\text { Kinerja Operasional } \rightarrow \text { Minat } \\
\text { Beli }\end{array}$ & 2,313 & 0,021 \\
\hline
\end{tabular}

Berdasarkan hasil pegujian, maka variabel kepercayaan terhadap minat beli mrmiliki nilai t-value sebesar 3,882 dan p-value sebesar 0,000 yang berarti H1 tidak ditolak karena tvalue lebih besar dari 1,96 dan p-value kurang dari 0,5. Jadi kesimpulannya kepercayaan memiliki pengaruh positif yang signifikan terhadap minat beli pada pelanggan Lazada di Jakarta Barat.

Berdasarkan hasil pegujian, maka variabel persepsi harga terhadap minat beli mrmiliki nilai t-value sebesar 1,311 dan p-value sebesar 0,190 yang berarti $\mathrm{H} 1$ ditolak karena t-value lebih kecil dari 1,96 tetapi p-value kurang dari 0,5. Jadi kesimpulannya persepsi harga 
memiliki pengaruh negatif yang signifikan terhadap minat beli pada pelanggan Lazada di Jakarta Barat.

Berdasarkan hasil pegujian, maka variabel kinerja operasional terhadap minat beli mrmiliki nilai t-value sebesar 2,313 dan p-value sebesar 0,021 yang berarti H1 tidak ditolak karena t-value lebih besar dari 1,96 dan p-value kurang dari 0,5. Jadi kesimpulannya kinerja operasional memiliki pengaruh positif yang signifikan terhadap minat beli pada pelanggan Lazada di Jakarta Barat.

\section{DISKUSI}

Hasil pengujian hipotesis pertama pada penelitian ini menunjukkan bahwa Kepercayaan dapat mempengaruhi Minat beli pada pelanggan Lazada di daerah Jakarta Barat secara positif dan signifikan yang berarti hipotesis tersebut tidak ditolak. Hasil pada penelitian ini sesuai dengan penelitian yang dilakukan oleh Mahmud, Dwivedi, Kumar, Davies, Rana, dan Baabdullah (2018) yang berjudul "Purchase intention in an electronic commerce ecironment: A trade-off between controlling measures and operational performance." Yang menunjukkan bahwa kepercayaan memiliki pengaruh yang positif signifikan pada minat beli konsumen dalam lingkungan e-commerce. Pada penelitian yang dilakukan oleh Mahmud dkk (2018) dilakukan dengan cara pengambilan sampel secara acak dan terkumpul sampel sebanyak 200 sampel dari 269 sampel yang dikumpulkan sebelumnya. 200 sampel tersebut dipilih sesuai dengan pengalaman mereka dalam membeli di e-commerce dan frekuensi interaksi dengan $e$ commerce. Tong dan Su (2018) pada penelitiannya yang berjudul "Exploring young consumers' trust and purchase intention of organic cotton apparel." Menyatakan bahwa kepercayaan konsumen mengenai konsep perdagangan yang adil dan atribut produk memainkan peran penting dalam mengarahkan minat beli pelanggan.

Hasil pengujian hipotesis kedua pada penelitian ini menunjukkan bahwa Persepsi harga dapat mempengaruhi Minat beli pada pelanggan Lazada di daerah Jakarta Barat secara negatif dan signifikan yang berarti hipotesis tersebut ditolak. Hasil pada penelitian ini tidak sesuai dengan penelitian yang dilakukan oleh Mahmud, Dwivedi, Kumar, Davies, Rana, dan Baabdullah (2018) yang berjudul "Purchase intention in an electronic commerce ecironment: A trade-off between controlling measures and operational performance." Yang menunjukkan hasil persepsi harga memiliki pengaruh yang positif signifikan pada minat beli konsumen dalam lingkungan e-commerce. Jamaludin, Ariffin dan Hidayat (2015) yang berjudul "Pengaruh Promosi Online Dan Persepsi Harga Terhadap Keputusan Pembelian (Survei Pada Pelanggan Aryka Shop di Kota Malang)" menyatakan bahwa harapan pelanggan dalam melakukan pembelian terbentuk dari pengalamannya sendiri dengan situasi yang sama, rekomendasi dari teman sendiri atau rekomendasi dari Lembaga (media masa, pemerintah dan lain sebagainya.)

Hasil pengujian hipotesis ketiga pada penelitian ini menunjukkan bahwa Kinerja Operasional dapat mempengaruhi Minat beli pada pelanggan Lazada di daerah Jakarta Barat secara positif dan signifikan yang berarti hipotesis tersebut tidak ditolak. Hasil dalam penelitian ini sesuai dengan penelitian yang dilakukan oleh Mahmud, Dwivedi, Kumar, Davies, Rana, dan Baabdullah (2018) yang berjudul "Purchase intention in an electronic commerce ecironment: A trade-off between controlling measures and operational performance." Yang menunjukkan bahwa kinerja operasi memiliki pengaruh yang positif signifikan pada minat beli konsumen dalam lingkungan e-commerce. Penelitian yang dilakukan Mahmud, Dwivedi, Kumar, Davies, Rana, dan Baabdullah (2018) juga menyatakan bahwa jika adanya langkah keamanan dalam bidang teknologi yang lebih kuat agar dapat menghindari adanya pencurian identitas, kehilangan produk, dan waktu dalam penggunaan maka dapat menimbulkan adanya minat beli dalam benak konsumen. 


\section{PENUTUP}

Kepercayaan memiliki efek positif yang signifikan terhadap Minat beli pada pelanggan Lazada di daerah Jakarta Barat. Kepercayaan konsumen terhadap sebuah produk memainkan peran penting dalam mengarahkan minat beli pelanggan. Persepsi harga memiliki efek negatif yang signifikan pada Minat beli pada pelanggan Lazada di daerah Jakarta Barat. Persepsi harga dalam melakukan pembelian terbentuk dari pengalamannya sendiri dengan situasi yang sama, rekomendasi dari teman sendiri atau rekomendasi dari Lembaga (media masa, pemerintah dan lain sebagainya). Kinerja Operasional memiliki efek positif yang signifikan terhadap Minat beli pada pelanggan Lazada di daerah Jakarta Barat. Kinerja operasional yang baik akan menciptakan langkah keamanan dalam bidang teknologi yang lebih kuat dan dapat menumbuhkan minat beli dalam benak konsumen.

Berdsarkan hasil penelitian, terdapat beberapa saran yang diharapkan dapat berguna bagi peneliti selanjutnya yaitu; menambahkan variabel lain yang dapat mempengaruhi minat beli seperti persepsi risiko, electronic word of mouth, persepsi nilai, perilaku konsumen, promosi, lokasi, kualitas pelayanan, kualitas produk dan lain sebagainya. Dan juga disarankan untuk memperluas ruang lingkup penelitian yaitu tidak hanya dilakukan di daerah Jakarta barat saja.

\section{DAFTAR RUJUKAN}

Alfidella, S., Kusumo, D. S., \& Suwawi, D. D. J. (2015). Pengukuran Usability I-Caring Berbasis Iso 9241-11 Dengan Menggunakan Partial Least Square (PLS). eProceedings of Engineering, 2(1), 1747-1755.

Alibaba/Lazada: Raising the bet. (2017). FT.Com, Retrieved (Maret 2020) from https://search.proquest.com/docview/1924303873?accountid=45753

Aliyah, I. (2014). Penguatan Sinergi Antara Pasar Tradisional Dan Modern Dalam Rangka Mewujudkan Pemerataan Pembangunan Ekonomi Kerakyatan. JA! UBL, 4(2), 22-31.

Ariffin, S.K., Mohan, T., dan Goh, Y.N. (2018). Influence of consumers' perceived risk on consumers' online purchase intention. Journal of Research in Interactive Marketing, 12(3), 309-327.

Cámara, S. B., Fuentes, J. M., \& Marín, J. M. M. (2015). Cloud computing, Web 2.0, and operational performance. The International Journal of Logistics Management, 26(3), 426-458.

Chen, M. Y., \& Teng, C. I. (2013). A comprehensive model of the effects of online store image on purchase intention in an e-commerce environment. Electronic Commerce Research, 13(1), 1-23.

Delaperche, M. (2018). ENTREPRENEURIAL BRANDING AND PURCHASE INTENTION: THE MEDIATING ROLE OF TRUSTWORTHINESS. AU-GSB EJournal, 11(1), 47-57.

Garson, G. D. (2016). Partial Least Squares: Regression and Structural Equation Models. Asheboro, NC: Statistical Associates Publishers

Hair, J. F., Hult, G. T. M., Ringle, C. M., Sarstedt, M. (2014). A primer on partial least squares structural equation modelling (PLS-SEM). California: SAGE.

Harjati, L., \& Venesia, Y. (2015). Pengaruh kualitas layanan dan persepsi harga terhadap kepuasan pelanggan pada maskapai penerbangan Tiger Air Mandala. E-Journal Widya Ekonomika, 1(1), 64-74.

Iprice Insights. (2020). Peta E-Commerce Indonesia. Retrieved (Maret 2020) from https://iprice.co.id/insights/mapofecommerce/ 
Jamali, S.K., Samadi, B. dan Marthandan, G. (2014). Prioritizing electronic commerce technologies in Iranian family SMEs. Interdisciplinary Journal of Contemporary Research in Business, 6(2), 148-180.

Jamaludin, A., Ariffin, Z., Hidayat, K. (2015). Pengaruh Promosi Online Dan Persepsi Harga Terhadap Keputusan Pembelian (Survei Pada Pelanggan Aryka Shop di Kota Malang). Jurnal Administrasi Bisnis, 21(1), 1-8.

Janio: Asia's Logistic Simplified (2020). Overview of Indonesia's Online Consumers in Q4. Retrieved (Maret 2020) from https://janio.asia/id/sea/indonesia/indonesia-q4-consumeroverview/

Lazada. (2020). Tentang Lazada. Retrieved (Maret 2020) from https://www.lazada.co.id/about/

Lien, C. H., Wen, M. J., Huang, L. C., \& Wu, K. L. (2015). Online hotel booking: The effects of brand image, price, trust and value on purchase intentions. Asia Pacific Management Review, 20(4), 210-218.

Macchion, L., Moretto, A. M., Caniato, F., Caridi, M., Danese, P., \& Vinelli, A. (2017). International e-commerce for fashion products: What is the relationship with performance? International Journal of Retail \& Distribution Management, 45(9), 10111031.

Mahmud, A. S., Dwivedi, Y. K., Kumar, V., Davies, G., Rana, N., \& Baabdullah, A. (2019). Purchase intention in an electronic commerce environment. Information Technology \& People, 32(6), 1345-1375.

Moleong, J, L. (2014). Metode Penelitian Kualitatif, Edisi Revisi. PT Remaja Rosdakarya, Bandung.

Noor, J. (2017). Metodologi penelitian (skripsi, tesis disertai, dan karya ilmiah). Jakarta: Kencana.

Patanasiri, A., \& Krairit, D. (2019). A comparative study of consumers' purchase intention on different internet platforms. Mobile Networks and Applications, 24(1), 145-159.

Purnell, N. (2014, Nov 21). Startup aims to be amazon.com of indonesia; lazada tries to get a head start in a country where just a third of population has web access. Wall Street Journal (Online) Retrieved

from https://search.proquest.com/docview/1627152517?accountid=45753

Putra, A., \& Heriyanto, M. (2017). Pengaruh Iklan Dan Kepercayaan Merek Terhadap Minat Beli Konsumen (Studi Pada Texas Chicken Pekanbaru). Jurnal Online Mahasiswa Fakultas Ilmu Sosial dan Ilmu Politik Universitas Riau, 4(1), 1-11.

Ram, S. U., \& Gupta, M. (2019). Do HRD practices affect perceived market performance through operational performance? evidence from software industry. International Journal of Productivity and Performance Management, 68(1), 85-108.

Sucipto, M. C. (2018). Analisis Minat Masyarakat Dalam Berinvestasi Dinar (Studi Kasus Di Gerai Dinar Purwakarta). EKSISBANK, 2(2), 28-30.

Sugiyono. (2013). Metode Penelitian Kuantitatif, Kualitatif Dan R\&D. Bandung : CV. Alfabeta.

Sugiyono. (2016). Metode Penelitian Kuantitatif, Kualitatif Dan R\&D. Bandung : CV. Alfabeta.

Tangmanee, C., \& Rawsena, C. (2016). Direct and Indirect Effects of Perceived Risk and Website Reputation on Purchase Intention. International Journal of Research in Business and Social Science, 5(6), 2147-4478.

Thamizhvanan, A., \& Xavier, M. J. (2013). Determinants of customers' online purchase intention: an empirical study in India. Journal of Indian Business Research, 5(1), $17-$ 32.

Timotius, K. H. (2017). Pengantar Metodologi Penelitian: Pendekatan Manajemen Pengetahuan untuk Perkembangan Pengetahuan. Yogyakarta : Penerbit Andi. 
Tong, X., \& Su, J. (2018). Exploring young consumers' trust and purchase intention of organic cotton apparel. Journal of Consumer Marketing, 35(5), 522-532.

Yusup, F. (2018). Uji validitas dan reliabilitas instrumen penelitian kuantitatif. Tarbiyah: Jurnal Ilmiah Kependidikan, 7(1), 17-23.

Zietsman, M. L., Mostert, P., \& Svensson, G. (2019). Perceived price and service quality as mediators between price fairness and perceived value in business banking relationships. The International Journal of Bank Marketing, 38(1), 2-19. 